\title{
Validation and reliability of the School-age Hearing Screening Questionnaire in adolescent users of compressed audio file players
}

\author{
Lizbeth F. Toxtle, ${ }^{1}$ Esperanza Ramírez-Pérez,, ${ }^{2}$ lleana Gutiérrez-Farfán, ${ }^{1}$ Laura Alonso-Luján ${ }^{1}$ and \\ Selene Martínez-Payán ${ }^{1}$ \\ 'Department of Pediatric Audiology; ${ }^{2}$ Laboratory of Genetics, Secretaría de Salud, Instituto Nacional de Rehabilitación, Ciudad de México, Mexicoo
}

\begin{abstract}
Introduction: Frequent use of audio file players and volume intensity are risk factors for the development of hypoacusis. Objective: To validate the school-age hearing screening questionnaire (CUTAE, by its Spanish acronym) for hearing disorders detection in teenage users of compressed audio file players (CAFP). Methods: Adolescent CAFP users without hypoacusis or middle ear pathology were studied. The CUTAE was applied and audiometry was carried out. Reproducibility (intraclass correlation coefficient-ICC), internal consistency (Cronbach's alpha), face validity (Delphi technique), CUTAE-audiometry concurrent validity (Pearson's correlation) and predictive validity (multiple regression) of the questionnaire was assessed. Results: Fifty nine adolescents (118 ears), 66\% females, average age of 13 years, were assessed. Ninety ears had normal parameters, 18 showed a threshold decrease $<20 \mathrm{~dB}$, with morphology associated with acoustic trauma (AT) at $6 \mathrm{kHz}$ and 10 with AT. The questionnaire had an ICC of 0.788, a Cronbach alpha-value of 0.807 , Pearson's correlation values of 0.290 to $0.368(p<0.05)$; the predictive variables were usage hours, difficulty hearing others $(p<0.05)$ and type of buzzing $(p=0.07)$. Conclusion: The CUTAE has adequate clinimetric properties to be considered as a screening test in the detection of hearing disorders in adolescent users of CAFP.
\end{abstract}

KEY WORDS: Acoustic trauma. Recreational noise. Compressed audio file players. Adolescents.

\section{Introduction}

Noise-induced hearing loss ( $\mathrm{NIHL}$ ) occurs when an individual is continuously exposed to dangerous sound levels. Compressed audio file players (CAFP) frequent use and high volume levels of are considered risk factors in adolescents for the development of hearing loss in adulthood. ${ }^{1}$

NIHL and noise-induced threshold shifts (NITS) are assessed with pure tone audiometry, which is considered the gold standard for the diagnosis hearing loss; ${ }^{2,3}$ with this diagnostic resource, noise exposure, habits and symptoms are assessed in order to identify hearing disturbances. ${ }^{4}$

Hearing screening questionnaires should include aspects related to NIHL such as hearing loss, tinnitus and noise exposure. ${ }^{5,6}$ There are only few instruments of this type for early diagnosis of harm due to noise exposure in adolescents. ${ }^{5,7,8}$ In Mexico, the School-age Hearing Screening Questionnaire (CUTAE Cuestionario de Tamizaje Auditivo Escolar) was designed, ${ }^{4}$ which is able to detect disturbances in CAFP adolescent users; however, its clinimetric properties were not assessed. Our purpose was to validate $\mathrm{CU}$ TAE capability to detect hearing damage in adolescents exposed to noise and to the use of CAFP.

\section{Method}

The investigation was carried out at the Audiology Department of the National Institute of Rehabilitation in Mexico City, and the sample was obtained at two secondary schools. Adolescent CAFP users of between 12
Correspondence:

Esperanza Ramírez-Pérez

E-mail: eramirez@inr.gob.mx
Date of reception: 16-02-2017

Date of acceptance: : 09-11-2017

DOI://dx.doi.org/10.24875/GMM.M18000148
Gac Med Mex. 2018;154:252-255

Contents available at PubMed www.gacetamedicademexico.com 
Table 1. Changes to the School-age Hearing Screening Questionnaire questions

\begin{tabular}{|c|c|c|c|}
\hline Question & Original version & Modified version & \\
\hline 2 & $\begin{array}{l}\text { Under what circumstances have you been exposed to } \\
\text { noise? Attending parties, bars or clubs }\end{array}$ & Parties, family entertainment center (videoga & nes) \\
\hline 3 & $\begin{array}{l}\text { In the past } 3 \text { months, how many times have you attended } \\
\text { a concert, bar or club, loud parties, movie theater or } \\
\text { theater or places with fireworks? }\end{array}$ & "Bar or club" was eliminated & 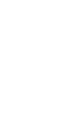 \\
\hline 7 & $\begin{array}{l}\text { Type of earphones: } \\
\text {-On-ear } \\
\text {-Earbuds } \\
\text {-In-ear }\end{array}$ & & (2) \\
\hline 12 & $\begin{array}{l}\text { Mark the volume you use most commonly in your Mp3 } \\
\text { player }\end{array}$ & & $\frac{1}{\varrho}$ \\
\hline 13 and 14 & $\begin{array}{l}\text { Have you ever experienced any type of hearing problems } \\
\text { such as buzzing, pain or hearing difficulty? } \\
\text { What problems have you experienced? }\end{array}$ & $\begin{array}{l}\text { Which of the following discomforts have you } \\
\text { experienced? }\end{array}$ & $\frac{2}{\frac{5}{2}}$ \\
\hline
\end{tabular}

and 16 years of age, of either gender, without a history of hearing loss secondary to hereditary or congenital factors or middle ear pathology were included.

The CUTAE measures exposure to CAFP, noisy environment, usage hours, sound volume and hearing loss in children and adolescents to identify hearing disturbances. It contains 26 questions with multiple answer options. It discriminates between CAFP users and non-users, and between subjects with and without hearing disturbances. The authors granted their consent for its validation.

A group of audiology, otoneurology, speech therapy and instrument validation experts with 7 to 10 years' working experience was formed. Noise-exposure domains (attendance to concerts, high volume level, daily usage hours, type of earphones) and symptoms (hearing impairment, ear infection, buzzing, dizziness) were established. Instructions, language, comprehension and question-answer options coherence were reviewed. The modified questions are shown in table 1. With the final version, the CUTAE reproducibility was measured by applying it on two occasions, with 3 weeks distance between the first and the second. ${ }^{9}$

Prior to the CUTAE application, informative talks and leaflets were provided to teachers and parents on the use of CAFPs and its relationship with hearing damage.
With parents' written informed consent, the students were brought to the Audiology Department accompanied by one teacher. Two doctors delivered the CUTAE and took the children's history, focusing on family or personal history of otic conditions or hearing loss, upper respiratory tract diseases and use of ototoxic agents, and carried out an otorhinolaryngologic examination.

Air tone audiometry and logoaudiometry (Madsen Orbiter $922^{\circledR}$ audiometer), as well as tympanometry (Madsen Zodiac $901^{\circledR}$ impedance tester) were carried out in a soundproof booth. Bone audiometry was performed in those in whom air conduction was observed to be lower than $20 \mathrm{~dB}$.

The output scale of the questionnaire was additive and a score was assigned to each answer option, with their weight and order being considered: 1 , no hearing damage and 5, highest damage; lowest score was 26 and highest $128 ;{ }^{10}$ it was used for all questions except for number 23 , where a visual scale with values ranging from 1 to 10 was viable.

Face validity was assessed with Delphi technique, internal consistency with Cronbach's alpha, test-test reproducibility with intraclass correlation coefficient (ICC) and concurrent validity (CUTAE-audiometry) with Pearson's correlation.11 
Table 2. School-age Hearing Screening Questionnaire concurrent validity with regard to audiometry

\begin{tabular}{lc}
\hline & Pearson's correlation* \\
\hline Left ear air conduction & \\
Attending concerts & 0.290 \\
Usage hours & 0.306 \\
Usage intensity & 0.309 \\
Difficulty listening people & 0.267 \\
Difficulty listening on the telephone & 0.331 \\
Television with high volume & 0.357 \\
& \\
Right ear air conduction & \\
Difficulty listening teachers & 0.291 \\
Need to have things repeated & 0.315 \\
Ear buzzing & 0.306 \\
Difficulty listening on the telephone & 0.368 \\
Television with high volume & 0.295 \\
Difficulty listening people & 0.294 \\
Buzzing frequency & 0.280 \\
Buzzing intensity & 0.295 \\
${ }^{*} \mathrm{p} \leq 0.05$ &
\end{tabular}

Two multiple regression models were estimated, one per ear; the dependent variable was air conduction, whereas independent variables were the CUTAE questions. The model was adjusted for age, school grade and gender. The level of significance was established at $p \leq 0.05$. The statistical program used was SPSS, version 15.

\section{Results}

Fifty-nine adolescents were studied, out of which $66 \%$ were females, and all were CAFP users; age average was 13 years. Of the 118 examined ears, air tone audiometry showed normal thresholds in 90, threshold below $20 \mathrm{~dB}$ with acoustic trauma (AT) at the $6 \mathrm{KHz}$ frequency in 18, grade I AT in 4, grade II AT in 4 and grade III AT in 2. Logoaudiometry and tympanometry were normal in all adolescents.

As for the properties of the questionnaire, the following results were obtained:

- Reliability: An ICC of $0.788(p<0.001)$ indicated that the instrument can be applied on different occasions without losing its clinimetric properties. ${ }^{11}$

- Internal consistency: Total Cronbach's alpha was 0.807 , in the noise exposure domain it was 0.555 and in the symptom domain it was 0.840 .

- Face and content validity: It was obtained by expert consensus.

- CUTAE-audiometry concurrent validity in both ears: Correlation of 0.290 to 0.368 between the questionnaire questions and the audiology test in both ears (Table 2).
In $49 \%$ of adolescents who attended concerts and parties once or twice within the previous 3 months normal audiometry was observed in comparison with $17 \%$ of those who did it more than 15 times in the same period $(p<0.05) ; 74 \%$ of those who used the CAFP between 1 and 2 hours per day had a normal audiometry in comparison with those who used it for more than 8 hours per day $(p<0.05) ; 5 \%$ of adolescents who used the player at home had AT ( $p<0.05)$. Volume level $>50$ to $100 \%$ of the player capacity was associated with hearing disturbance $(p<0.05)$ and AT $(p<0.012) ; 33 \%$ showed difficulty listening to teachers in class and listening on the telephone $(p<0.05)$.

The presence of tinnitus was associated with hearing disturbances in $33 \%$ of cases $(p<0.05)$. In addition, the type of buzzing is associated with hearing problems: adolescents who perceived a buzzing similar to motor noise had hearing problems in comparison with those who perceived a buzzing similar to the sound of an insect $(p<0.001)$. Table 3 shows the predictors for noise-induced hearing damage.

\section{Discussion}

The CUTAE is reproducible, reliable and valid. It measures noise exposure ${ }^{12,13}$ and symptoms $s^{12,14,15}$ with similar results to those published in other investigations where hearing loss due to recreational or social noise was assessed. ${ }^{15,16}$ Internal consistency of the instrument was similar to that reported by Bohlin ${ }^{17}$ and Gullone ${ }^{18}$ (Cronbach's alpha of 0.80 versus 0.88 ); there was adequate homogeneity between questions, so that it turned out to be a reliable screening test for the detection of hearing disturbances in CAFP adolescent users, among whom acoustic trauma was identified in $24 \%$ of ears, in contrast with $12.5 \%$ reported by Niskar $^{1}$ in children and adolescents with hearing loss induced by noise and $14 \%$ of hearing loss reported by Olunsanya. ${ }^{19}$ The high prevalence might be explained by the low awareness of adolescents about the damage caused by the use of CAFP and high volume levels in comparison with older young persons. ${ }^{20}$

Of the adolescents exposed to intense noise on more than 15 occasions within a 3-month period, $17 \%$ had hearing disturbances, which is lower than the 30 $\%$ rate observed by Jofre ${ }^{21}$ in young individuals exposed to sound intensities higher than those considered as occupational risk in activities such as attending clubs or concerts or playing in a rock band.

CAFP daily use was considered to be a risk factor for acoustic trauma: $25 \%$ of the sample had injuries 
Table 3. Predictors of hearing damage

\begin{tabular}{|c|c|c|c|c|}
\hline \multirow[t]{2}{*}{ Variables } & \multicolumn{2}{|c|}{ Non-standardized coefficients } & \multicolumn{2}{|c|}{$95 \% \mathrm{Cl}$ for $\beta$} \\
\hline & $\beta$ & Sig. & Lower & Upper \\
\hline \multicolumn{5}{|l|}{ Left ear air conduction } \\
\hline Player usage hours per day & 0.113 & 0.02 & 0.013 & 0.213 \\
\hline Difficulty listening on telephone & 0.168 & 0.01 & 0.04 & 0.296 \\
\hline \multicolumn{5}{|l|}{ Right ear air conduction } \\
\hline Type of buzzing & 0.070 & 0.07 & -0.006 & 0.146 \\
\hline Buzzing appearing for the first time & -0.121 & 0.07 & -0.255 & 0.013 \\
\hline
\end{tabular}

in both ears. Adolescents exceeded the noise daily dose recommended time by using the player for more than 8 hours; in the occupational setting this exposure is regarded as risky and is regulated by the Mexican Official Standard ${ }^{22}$ (noise daily dose of $90 \mathrm{~dB}$ in an 8-hour period).

With regard to sound intensity, an important variation was identified according to the context in which music is listened to: it was higher when practicing sports and when using public transport. ${ }^{13}$ In the analyzed adolescents, $44 \%$ listened to the player at home and, of this proportion, $5 \%$ had acoustic trauma.

The main symptom was tinnitus in $17 \%$ of the sample; it has been identified in 23 to $66 \%$ after noise exposure and it can be an early indicator of hearing loss. ${ }^{8,23-25}$

$\mathrm{NIHL}$ predictors were CAFP daily usage hours, difficulty listening on the telephone $(p<0.05)$ and, to a lesser extent, buzzing type and onset $(p=0.07)$, consistent with Ising observations, ${ }^{26}$ who reported that continuous noise exposure for 5 years causes hearing loss induced by noise louder than $10 \mathrm{~dB}$ at the end of this period. We conclude that CUTAE is a reliable screening test for the detection of hearing disturbances in CAFP adolescent users.

\section{References}

1. Niskar AS, Kieszak SM, Holmes AE, Esteban E, Rubin C, Brody D. Estimated prevalence of noise-induced hearing thresholds shifts among children 6 to 19 years of age: the Third National Health and Nutrition Examination Survey, 1988-1994, United States. Pediatrics. 2001;108,40-43.

2. Boccio C. Los adolescentes poseen hábitos de riesgo y signos precoces de disfunción coclear. Evid Actual Pract Ambul. 2005;8:172.

3. Bexelius C, Honeth L, Ekman A, Eriksson M, Sandin S, Litton JE, et al. Evaluation of an internet-based hearing test-comparison with established methods for detection of hearing loss. Med Internet Res. 2008;10:e32.

4. Gutiérrez-Farfán I, Alonso-Luján L, León-Hernández S. Correlación de test sobre exposición a ruido y hallazgos audiológicos en niños y adolescentes mexicanos. An Med Mex. 2008;53:143-148.
5. Penafiel E. Developing a questionnaire to assess noise exposure in children and teens. Tesis de pregrado, The Ohio State University, EE. UU., 2007.

6. Rawool V, Colligon-Wayne LA. Auditory lifestyles and beliefs related to hearing loss among college students in the USA. Noise Health. 2008;10:1-10

7. Muñoz K, Caballero A, White K. Effectiveness of questionnaires for screening hearing of school-age children: A comprehensive literature review. Int J Audiol. 2014;53:910-914.

8. Salazar AM, Vázquez L, Díaz P, Ramírez N, Solís F. Efecto del personal stereo en la audición para las altas frecuencias. C\&T; 2006;20:52-57.

9. Marx RG, Menezes A, Horovitz L, Jones EC, Warren RF. A comparison of two time intervals for test-retest reliability of health status instruments. $\mathrm{J}$ Clin Epidemiol. 2003;56:730-735.

10. Feinstein A. Clinimetrics. USA: Yale University Press; 1987.

11. Streiner D, Horman G, Cairney J. Health measurement scale: a practical guide to their development and use. USA: Oxford University Press; 1995.

12. Vogel I, Brug J, Van-Der-Ploeg C, Raat H. Young people's exposure to loud music: a summary of the literature. Am J Prev Med. 2007:33:124-133.

13. Breinbauer HA, Anabalón JL, Gutiérrez D, Caro J. Estimación de riesgos y hábitos de uso de reproductores de música personal en una muestra de población chilena. Rev Otorrinolaringol Cir Cabeza Cuello. 2011;71:31-38.

14. Fuentes E, Cardemil F. Validación de criterio y constructo para la creación de un cuestionario de exposición a ruido. Rev Otorrinolaringol Cir Cabeza Cuello. 2014;74:21-30.

15. Zenker F, Altahona MP, Barajas JJ. La exposición a ruido por actividades de ocio en adolescentes. Rev Logop Fon Audiol. 2001;21:173-180.

16. Biassoni EC, Serra MR, Villalobo J, Joekes S, Yacci MR. Hábitos recreativos en la adolescencia y salud auditiva. Interam $\int$ Psychol. 2008;42: 257-271.

17. Bohlin MC, Erlandsson SI. Risk behavior and noise exposure among adolescents. Noise Health. 2007;9:55-63.

18. Gullone E, Moore S, Moss S, Boyd C. The Adolescent Risk-Taking Questionnaire: development and psychometric evaluation. J Adolesc Res. 2000;15: 231-250.

19. Olunsanya B. Early detection of hearing impairment in a developing country: what options? Audiology. 2001;40:141-147.

20. Vogel I, Brug J, Hosli EJ, Van-Der-Ploeg C, Raat H. MP3 players and hearing loss: adolescents' perceptions of loud music and hearing conservation. J Pediatr. 2008;152:400-404.

21. Jofré D, De-La-Paz F, Platzer L, Anabalón JL, Grasset E, Barnafi N. Evaluación de la exposición a ruido social en jóvenes chilenos. Rev Otorrinolaringol Cir Cabeza Cuello. 2009;69:23-28.

22. Secretaría del Trabajo y Previsión Social. NOM-011-STPS-2001, norma oficial mexicana, condiciones de seguridad e higiene en los centros de trabajo donde se genere ruido. Diario Oficial de la Federación 2002 Abr 17.

23. Martin WH, Griest SE, Sobel JL, Howarth LC. Randomized trial of four noise-induced hearing loss and tinnitus prevention interventions for children. Inter J Audiol. 2013;52:S41-S49.

24. Muhr P, Rosenhall U. Self-assessed auditory symptoms, noise exposure, and measured auditory function among healthy young Swedish men. Int J Audiol. 2010;49:317-325.

25. Griest SE, Folmer RL, Martin WH. Effectiveness of "dangerous decibels", a school-based hearing loss prevention program. Am J Audiol. 2007;16:S165-S181.

26. Ising H, Babisch W, Hanee J, Kruppa B. Loud music and hearing risk. J Audiol Med. 1997;6:123-133. 